\title{
Ein Praxistag wie aus einem Actionfilm
}

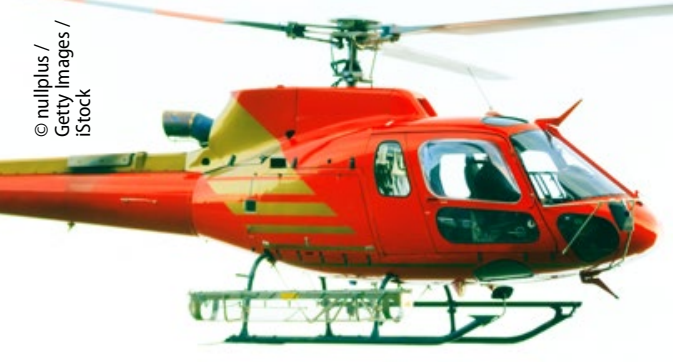

_ Ganz beiläufig berichtete mir neulich eine Patientin beim DMP Diabetes, dass sie seit dem Vortag einen schlaffen Arm habe. Das sei ganz plötzlich aufgetreten - aber ins Krankenhaus wolle sie auf keinen Fall!

Gerade wollte ich ihr erklären, dass sie das Symptom vielleicht doch etwas ernster nehmen sollte, als unser Gespräch durch einen Anruf jäh unterbrochen wurde. Mein Team meldete mir einen akuten Notfall: Im EKG-Raum

lag ein Patient mit Herzinfarkt.

Ich versorgte den Patienten fachgerecht und war froh, als nach kurzer Zeit ein RTW an der Praxis ankam. Allerdings musste ich hören, dass alle bodengebundenen Notärzte gerade anderweitig im Einsatz waren. Man sagte mir aber, dass eine Notärztin per Hubschrauber dazu kommen werde.

Diese Information hörte der Patient, woraufhin er in ein Lamento verfiel und immer wieder ausrief: „Ich werde nicht fliegen, ich werde nicht fliegen!“ Seine Ehefrau bekam begleitend lautstarke Weinkrämpfe. Beide hatte nicht verstanden, dass der Transport ins Krankenhaus unkompliziert mit dem RTW erfolgen sollte.

Mit Mühe konnte ich die beiden beruhigen und schließlich den Patienten an den Rettungsdienst übergeben. Danach wollte ich schleunigst zurück zu der Dame mit dem Schlaganfall. Auf dem Flur lief ich allerdings zwei Polizisten in die Arme, von denen einer die Hand an der Dienstwaffe hatte - gerade so, als wäre er kurz davor, sie in meiner Praxis zu ziehen.

Ein kurzer verbaler Austausch ergab, dass die beiden Ordnungshüter die Notärztin vom Hubschrauberlandeplatz zur Praxis befördert hatten. Warum sie nun mitten in der Praxis standen und eine Umfeldsicherung durchführten, habe ich dagegen nicht verstanden. Es wird wohl ihr Geheimnis bleiben.

Endlich zurück im Sprechzimmer empfing mich die Patientin mit der Armparese mit den Worten: „Immer sind alle anderen wichtiger!" Stimmt wohl, dachte ich mir - und das gilt vor allem für uns Ärzte. „Und genau aus diesem Grund werde ich mich jetzt um Sie kümmern!“, sagte ich.

Dr. Claudia Krite-Anthes, Springe

\section{Romantisches Echo aus der Vergangenheit}

_ Wenn man als Hausarzt in der Gegend praktiziert, in der man aufgewachsen ist, kann einen jederzeit unverhofft die Vergangenheit einholen. So wie neulich bei einem Hausbesuch in einem Altenheim der Nachbarstadt, als mich eine Patientin fragte, ob ich in Aurich das Gymnasium besucht hätte - und mich an ihre Tochter Ina, eine damalige Klassenkameradin, erinnern könne. Sofort wurde ich zurückversetzt an den Anfang der 1970er-Jahre, und vor meinem geistigen Auge sah ich meine erste schüchterne Annäherung an das andere Geschlecht.

Es war auf der Rückkehr von einer Klassenfahrt zum Abschluss der Mittelstufe, als wir einen Halt in Bremen einlegten. Bei meinem Streifzug durch den Bahnhofsbereich traf ich Ina, die eben- falls allein unterwegs war. Wir taten uns für ein Essen in einem Schnellrestaurant zusammen. Ich war sehr aufgeregt und ungeschickt. Sie war sehr zurückhaltend und lieb. Nach einer Stunde trennten sich unsere Wege wieder.

Es war doch sehr nett, nach so vielen Jahren wieder an dieses unvergleichliche Erlebnis erinnert zu werden.

Dr. Hinrich Hinrichs, Großefehn 